\title{
Intracerebral Abscess Caused by Actinomyces israelii
}

Dinko Stimac ${ }^{1}$, Dragan Jankovic ${ }^{2,3}$, Ljiljana Peric ${ }^{4}$, Kata Anic ${ }^{4}$, Christopher Nimsky ${ }^{5}$

1. Neurosurgery, Health center of Primorje - Gorski Kotar county, Rijeka, HRV 2. Neurosurgery, University Medical Centre of the Johannes Gutenberg University of Mainz, Mainz, DEU 3. Medicine, University of Zagreb, Zagreb, HRV 4. Infectious Diseases, University Hospital Osijek, Osijek, HRV 5. Neurosurgery, University Marburg, Marburg, DEU

Corresponding author: Dinko Stimac, dinkostimac@hotmail.com

\begin{abstract}
We describe a case of 49-years old female with a medical history of penicillin allergy, who suffered from brain infection caused by Actinomyces israelii. Therefore, the available therapy was metronidazole, ceftriaxone, and chloramphenicol. Due to a deterioration of the general and neurological condition of the patient, it was decided to perform a scratch skin test on penicillin, which was negative. After that, penicillin was administrated parenterally. The patient showed no hypersensitive reaction. Improvement was achieved. The patient underwent three subsequent surgeries due to primary and recurrent brain abscesses. There was a distinct improvement in her clinical status. Two months after the second re-surgery, the control computed tomography showed complete regression of the abscess.
\end{abstract}

Brain abscess caused by an Actinomycess israelii is very resistant to medication. However, surgical evacuation significantly accelerates the healing process. A good medication therapy is crucial and in most cases the drug of choice is penicillin. We emphasize the importance of a combined approach for treating this unusual brain infection.

Categories: Infectious Disease, Neurosurgery

Keywords: actinomyces, brain abscess, surgery

\section{Introduction}

Actinomyces israelii is a gram-positive bacteria within the genus Actinomyces which is the most frequent cause of an actinomycosis, a noncontagious, slow, purulent infection [1-3]. Actinomycotic brain infections (i.e. brain abscess, subdural and extradural empyema) are rare, but serious, life threatening infections. In a large series of pyogenic abscesses, this genus was the etiological agent in fewer than $2 \%$ of cases [2]. The present report describes a case of cranial actinomycosis in a 49-year-old female in whom no other sites of infection were found.

Review began $11 / 05 / 2020$ Review ended 12/05/2020 Published 12/13/2020

\section{(c) Copyright 2020}

Stimac et al. This is an open access article distributed under the terms of the Creative Commons Attribution License CC-BY 4.0., which permits unrestricted use, distribution, and reproduction in any medium, provided the original author and source are credited.

\section{Case Presentation}

A 49-years old female suffered from neck stiffness, paresthesia in her right leg and headache. A computed tomography (CT) scan of the brain revealed an expansive mass deeply in the left parieto-occipital region (Figure 1). The mass had a central zone of hypodensity surrounded by a ring of marked perifocal edema. The blood count results showed elevated erythrocyte sedimentation rate and leukocytosis. She had a history of good physical health and did not report any foci of infection, sinusitis, or head trauma.

Two days later, her state of consciousness progressively worsened accompanied with the development of right leg paresis. Antiedematous therapy with corticosteroids was administrated and the neurological status gradually improved. The patient underwent a left sided osteoplastic parieto-occipital craniotomy six days later. An abscess with thick fibrous capsule was found intraoperativly. The capsule was opened and $15 \mathrm{ml}$ of yellowish-green pus was removed. Obtained samples of pus together with small pieces of infected capsule and removed tissue were submitted for bacteriological tests. For complete abscess and capsule removal, the Cavitron Ultrasonic Surgical Aspirator (CUSA) was used. The CUSA was applied in the lowest mode of irrigation to prevent spreading of infection. The surgical procedure went well, without complications. The histopathologic examination of the excised lesion revealed the presence of Actinomyces israelii (Figure 2 and 3). 


\section{Cureus}

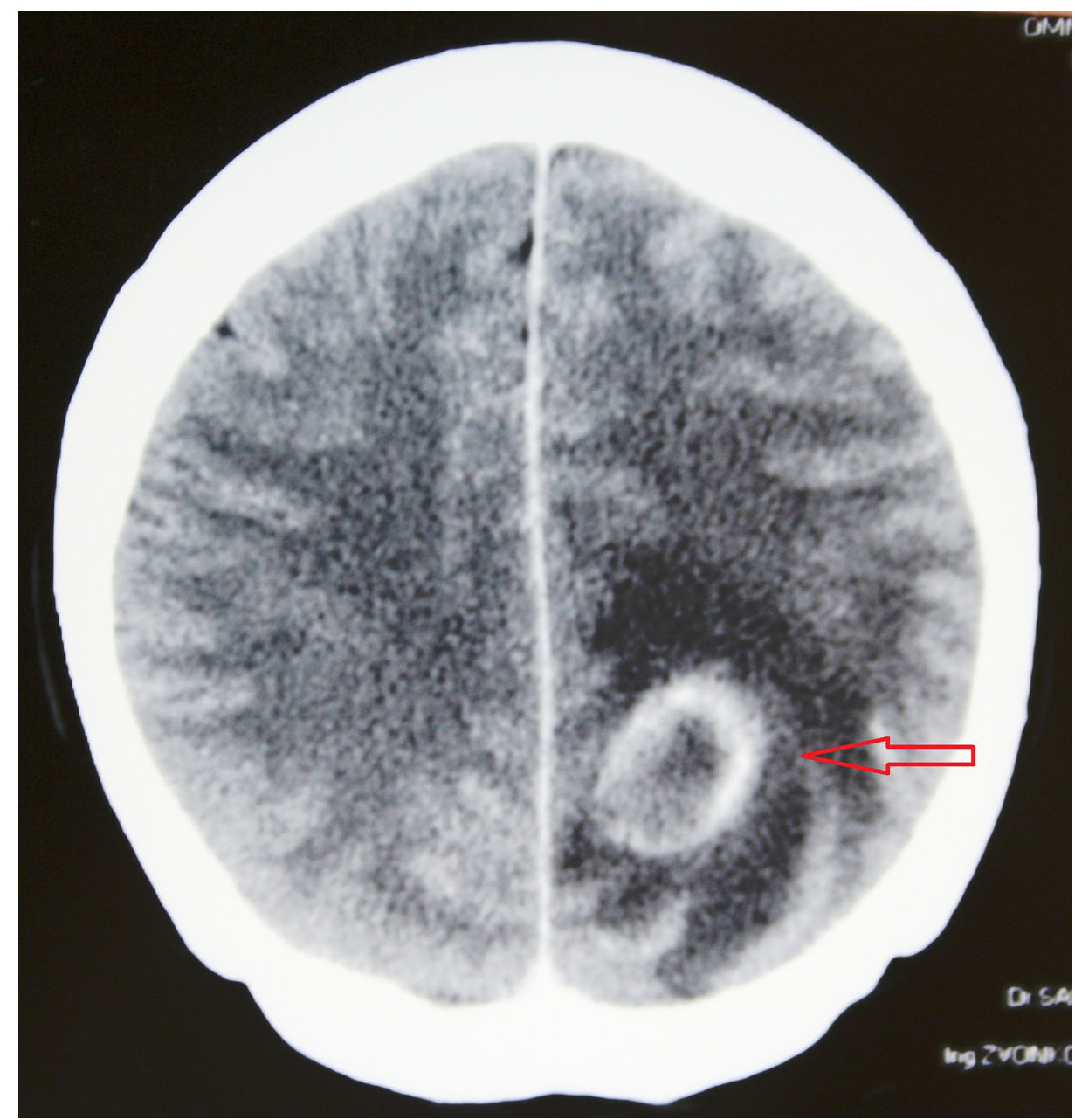

FIGURE 1: A CT scan of the brain with contrast medium obtained preoperatively revealed an expansive mass deeply in the left parietooccipital region. A mass has the central zone of hypodensity surrounded by a ring of marked perifocal edema. 


\section{Cureus}

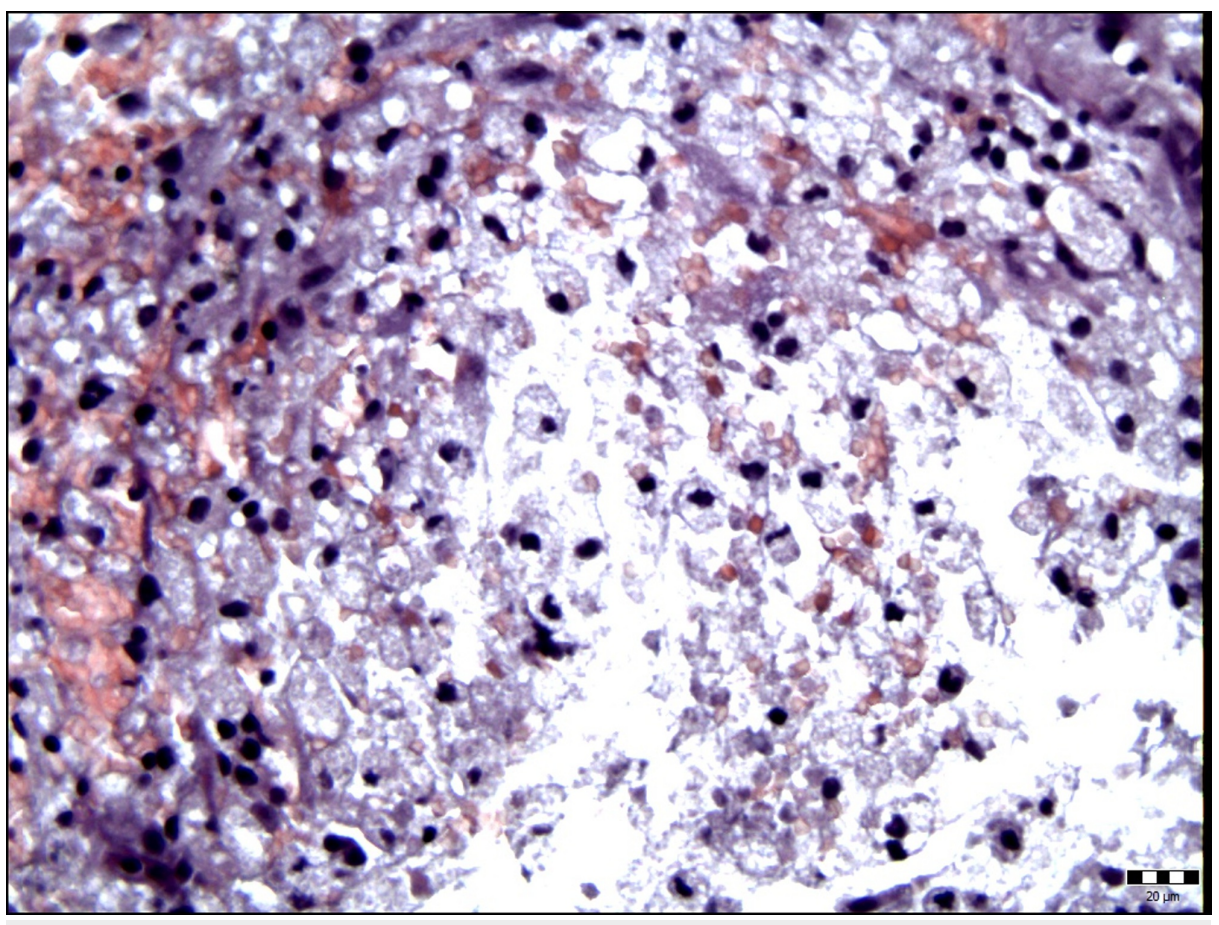

FIGURE 2: Histological examination showed brain tissue diffusely permeated with mononuclear inflammatory cells of the foamy cytoplasm with foamy macrophages and lymphocytes (hematoxylin-eosin stain, original magnification $\times 400$ ).

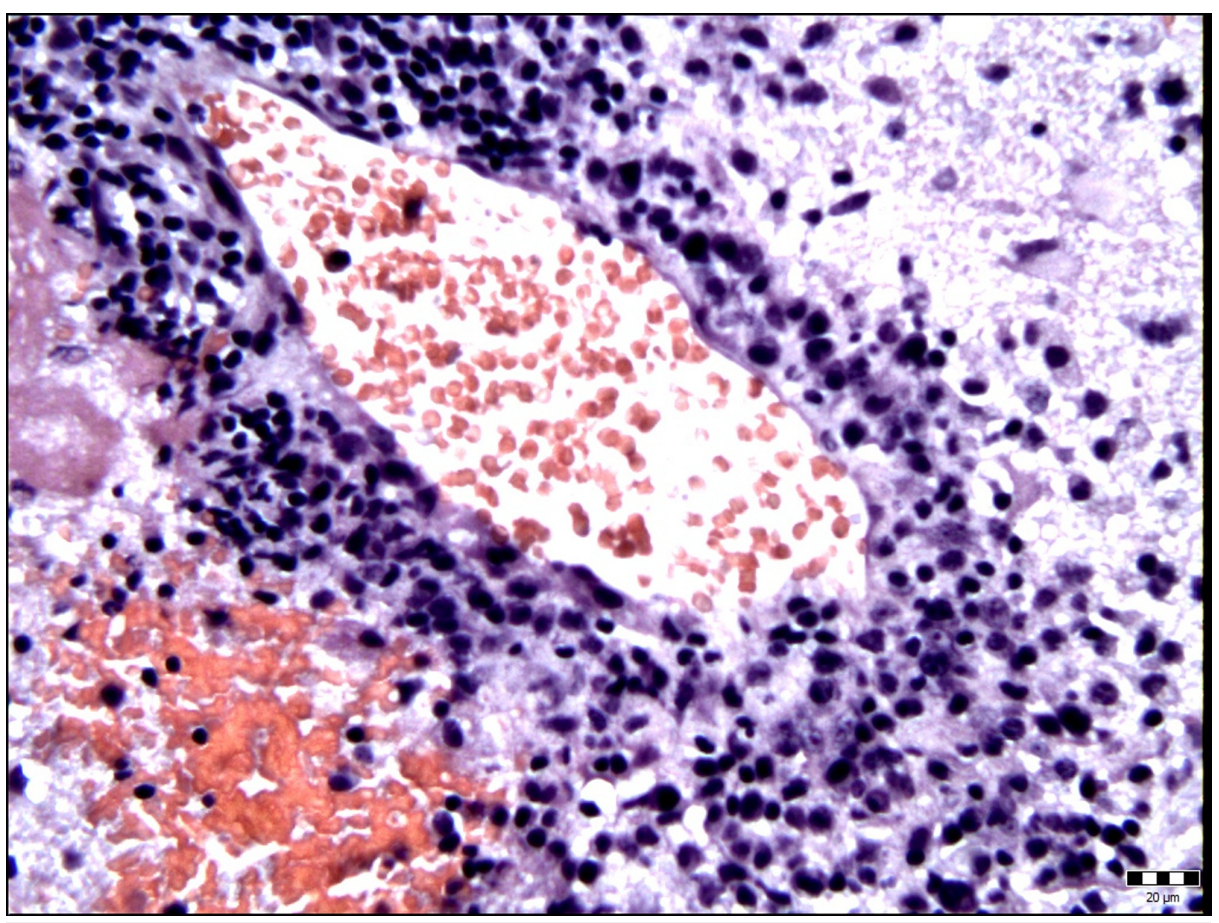

FIGURE 3: Edematous and reactively altered brain with perivascular accumulation of mononuclear inflammatory cells (hematoxylin-eosin stain, original magnification $\times 400$ ). 


\section{Cureus}

chloramphenicol were administrated through intravenous infusion.

A postoperative CT scan of the brain was performed three weeks after surgery and revealed a newly formed abscess in close proximity to the one removed before. The abscess was in its early stage of encapsulation and was close to $30 \mathrm{~mm}$ in diameter. A re-craniotomy was performed and the abscess was removed completely. Postoperatively, the patient's clinical status worsened with development of sensomotoric dysphasia and alteration in conscience. Due to worsening neurological status, it was decided to perform a scratch skin test with penicillin. The test was negative and a parenteral administration of penicillin did not show an allergic reaction. Antibiotic therapy with crystacillin, ceftriax and metronidazole was continued. Rapid improvement of the clinical status was noticed. Markers for a blood infection normalized within 2 weeks. The third week after the second surgery, a control CT scan revealed another newly incapsulated process in the proximity of removed ones before, located more towards the cortex (Figure 4).

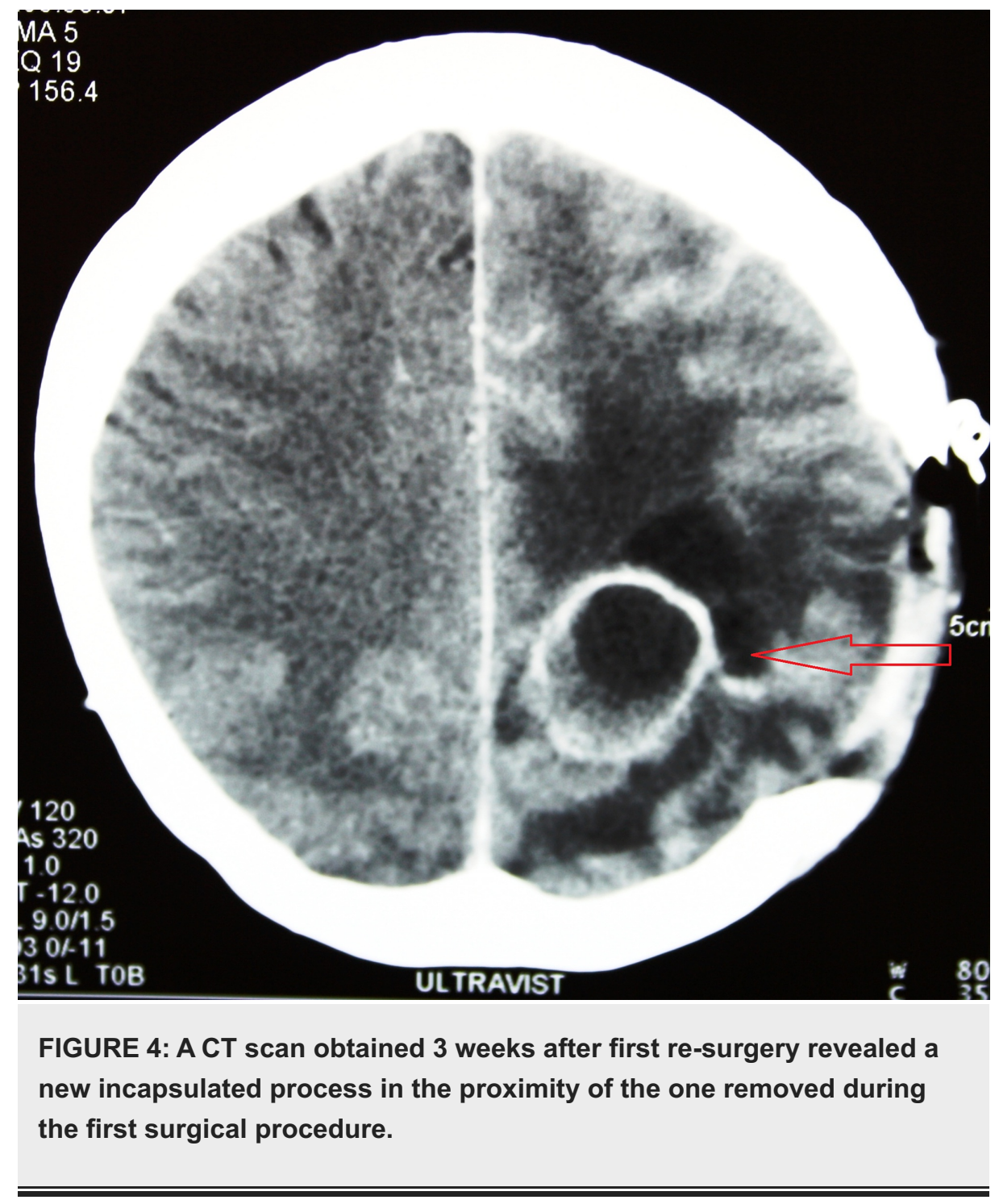

The third surgery was done and again the abscess was removed completely. The same antimicrobial therapy was continued.

A control CT scan of the brain obtained two months later showed complete disappearance of the abscess (Figure 5). The patient continued with antibiotic treatment for one month and was discharged fully recovered. 


\section{Cureus}

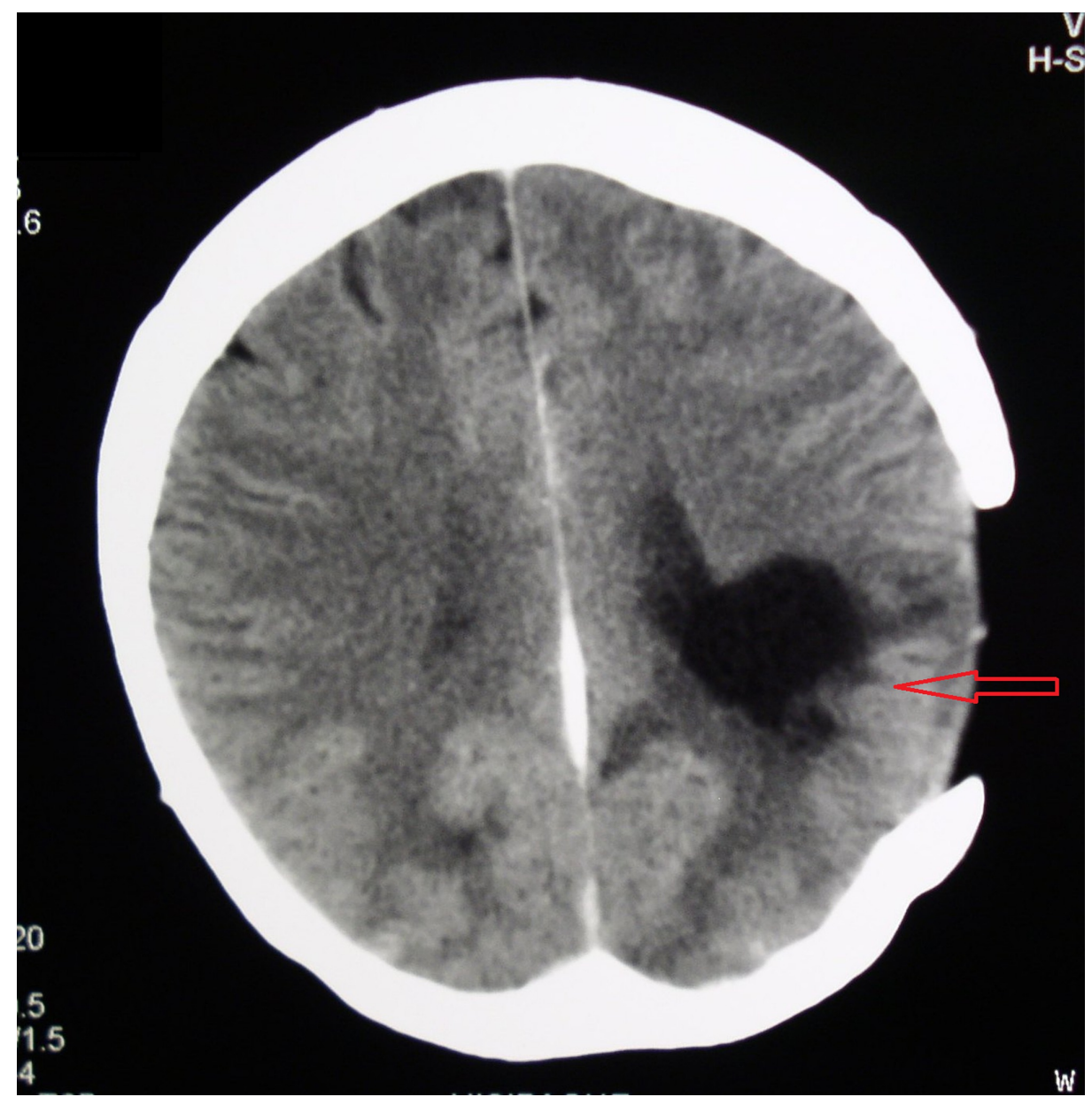

FIGURE 5: A CT scan obtained two months after the second re-surgery for the abscess. A porencephalic cyst after the abscess removal is visible. During the discharge from the hospital the patient has been without a neurological deficit.

At the five months after surgery, the clinical follow-up examination confirmed that she had returned to her normal activities and was free of neurological deficits.

\section{Discussion}

An Actinomyces israelii is a gram-positive, non-acid-fast, anaerobic or microaerophilic bacterium [4]. Actinomyces spp. is part of the normal commensal flora of the mouth, lower gastrointestinal tract, and female genital tract. [5]. They are very low virulent bacteria to humans because they need a mucous membrane integrity break along with the presence of devitalized tissue and other bacterial species acting as co-pathogens to cause an infection. In the pathologic state or immunodepletion, infections may occur in a local or disseminated form [6].

An intracranial actinomycosis in $45-50 \%$ cases can arise as direct extension from surrounding structures, secondary in $25 \%$ by hematogenous spread from remote site or in $10 \%$ from cranial trauma or even surgery. In $15 \%$ of all cases, the source of infection cannot be identified. Multiple brain abscesses are reported in 2$15 \%$ of cases [1].

The patients are mostly affected in the third decade of life with a male predominance [3]. Pediatric cerebral actinomycosis cases are rare. A cerebral abscess caused by Actinomyces israelii was detected in a 10-year-old boy with congenital heart disease and successfully treated with neurosurgical excision followed by a 4-week course of ceftriaxone [7].

The process of intracerebral abscess formation goes through four stages. The first stage (early cerebritis) is characterized with poorly demarked surrounding tissue and presence of a perivascular infiltration. In the second stage (late cerebritis), a reticular matrix and development of a necrotic center are seen. In the third stage (early incapsulation), a necrotic center with neovascularisation is observed. The fourth stage (late 
incapsulation) differentiates clear distinction between the collagen capsule, a necrotic center, and reactive gliosis around the capsule [8].

The patients have signs of increased intracranial pressure such as headaches, nausea, and lethargy, followed by high C-reactive protein (CRP) levels and leukocytosis over 10,000, negative hemoculture and over $90 \%$ positive lumbar puncture. Once the infection is established, spread through surrounding tissues begins with possible hematogenous dissemination at any stage of disease. In most cases of a central nervous system (CNS) involvement, it is thought to have spread from an extracranial source. When the infection has a cervico-facial localization, the principal route of entry may be the oral cavity via periapical dental granuloma $[9,10,11]$.

In the early stages of abscess development (stages one and two) and an abscesses size of under $2.5 \mathrm{~cm}$ in diameter, the medical therapy is the method of choice. Antibiotic treatment is based on high doses of penicillin for a long time (6-12 months). However, Jamjoom et al. reported three cases cured by shorter antibiotic treatment [12]. The surgical intervention should be reserved for abscesses larger than $2.5 \mathrm{~cm}$ and in all lesions with presence of a capsule. In our case, a craniotomy was performed based on the neuroradiological findings of perifocal edema and presence of a capsule.

\section{Conclusions}

The treatment strategy is based on the multidisciplinary approach of neurosurgeons, neuroradiologists and infectologists, while the outcome of treatment is the result of a combination of targeted antibiotic therapy and adequate surgical intervention. The choice of treatment depends on the size of the abscess, the stage of abscess formation, and the neurological status of the patient.

\section{Additional Information \\ Disclosures}

Human subjects: Consent was obtained by all participants in this study. Conflicts of interest: In compliance with the ICMJE uniform disclosure form, all authors declare the following: Payment/services info: All authors have declared that no financial support was received from any organization for the submitted work. Financial relationships: All authors have declared that they have no financial relationships at present or within the previous three years with any organizations that might have an interest in the submitted work. Other relationships: All authors have declared that there are no other relationships or activities that could appear to have influenced the submitted work.

\section{References}

1. Dailey AT, LeRoux PD, Grady MS: Resolution of an actinomycotic abscess with nonsurgical treatment: case report. Neurosurgery. 1993, 32:134-6. 10.1227/00006123-199301000-00022

2. Peabody JW, Seabury JH: Actinomycosis and nocardiosis. A review of basic differences in therapy . Am J Med. 1960, 28:99-115. 10.1016/0002-9343(60)90226-6

3. Wong VK, Turmezei TD, Weston VC: Actinomycosis. BMJ. 2011, 343:6099. 10.1136/bmj.d6099

4. Ham HY, Jung S, Jung TY, Heo SH: Cerebral actinomycosis : unusual clinical and radiological findings of an abscess. J Korean Neurosurg Soc. 2011, 50:147-150. 10.3340/jkns.2011.50.2.147

5. Valour F, Sénéchal A, Dupieux C, et al.: Actinomycosis: etiology, clinical features, diagnosis, treatment, and management. Infect Drug Resist. 2014, 7:183-197. 10.2147/IDR.S39601

6. Hovi L, Saarinen UM, Donner U, Lindqvist C: Opportunistic osteomyelitis in the jaws of children on immunosuppressive chemotherapy. J Pediatr Hematol Oncol. 1996, 18:90-94. 10.1097/00043426-19960200000018

7. Olah E, Berger C, Boltshauser E, Nadal D: Cerebral actinomycosis before adolescence. Neuropediatrics. 2004, 35:239-41. 10.1055/s-2004-820895

8. Osborn A.G: Congenital, acquired pyogenic and acquired viral infections. In: Osborn A., editor. Imaging, Pathol. Anat. Amirsys; Salt Lake. Osborn's brain. Osborn A.G (ed): Elsevier, Philadelphia; 2017.

9. Bolton CF, Ashenhurst EM: Actinomycosis of the brain; case report and review of the literature . Can Med Assoc J. 1964, 90:922-928.

10. Olson TS, Seid AB, Pransky SM: Actinomycosis of the middle ear. Int J Pediatr Otorhinolaryngol. 1989, 17:51-55. 10.1016/0165-5876(89)90293-0

11. Salvati M, Ciappetta P, Raco A, Artico M, Artizzu S: Primary intracranial actinomycosis. report of a case and review of the literature. Zentralbl Neurochir. 1991, 52:95-98.

12. Jamjoom AB, Jamjoom ZA, al-Hedaithy SS: Actinomycotic brain abscess successfully treated by burr hole aspiration and short course antimicrobial therapy. Br J Neurosurg. 1994, 8:545-50. 